Supplement of Geosci. Model Dev., 13, 3553-3569, 2020

https://doi.org/10.5194/gmd-13-3553-2020-supplement

(C) Author(s) 2020. This work is distributed under

the Creative Commons Attribution 4.0 License.

(c) (1)

Supplement of

\title{
A multirate mass transfer model to represent the interaction of multicomponent biogeochemical processes between surface water and hyporheic zones (SWAT-MRMT-R 1.0)
}

Yilin Fang et al.

Correspondence to: Yilin Fang (yilin.fang@pnnl.gov)

The copyright of individual parts of the supplement might differ from the CC BY 4.0 License. 


\section{Contents of this file}

1. Table S1

2. Figure $\mathrm{S} 1$

Table S1. Vertical and lateral residence times at selected reaches along the Columbia River.

\begin{tabular}{lll}
\hline Reach number & Vertical RT $(\mathrm{h})$ & Lateral RT $(\mathrm{h})$ \\
\hline 27 & 8.98 & 1380 \\
28 & 8.98 & 1380 \\
20 & 8.98 & 1380 \\
24 & 8.99 & 1380 \\
43 & 143 & 46100 \\
53 & 143 & 46100 \\
67 & 143 & 46100 \\
77 & 8.49 & 408 \\
88 & 7.88 & 408 \\
93 & 112 & 22100 \\
100 & 258 & 93800 \\
101 & 267 & 93800 \\
\hline
\end{tabular}




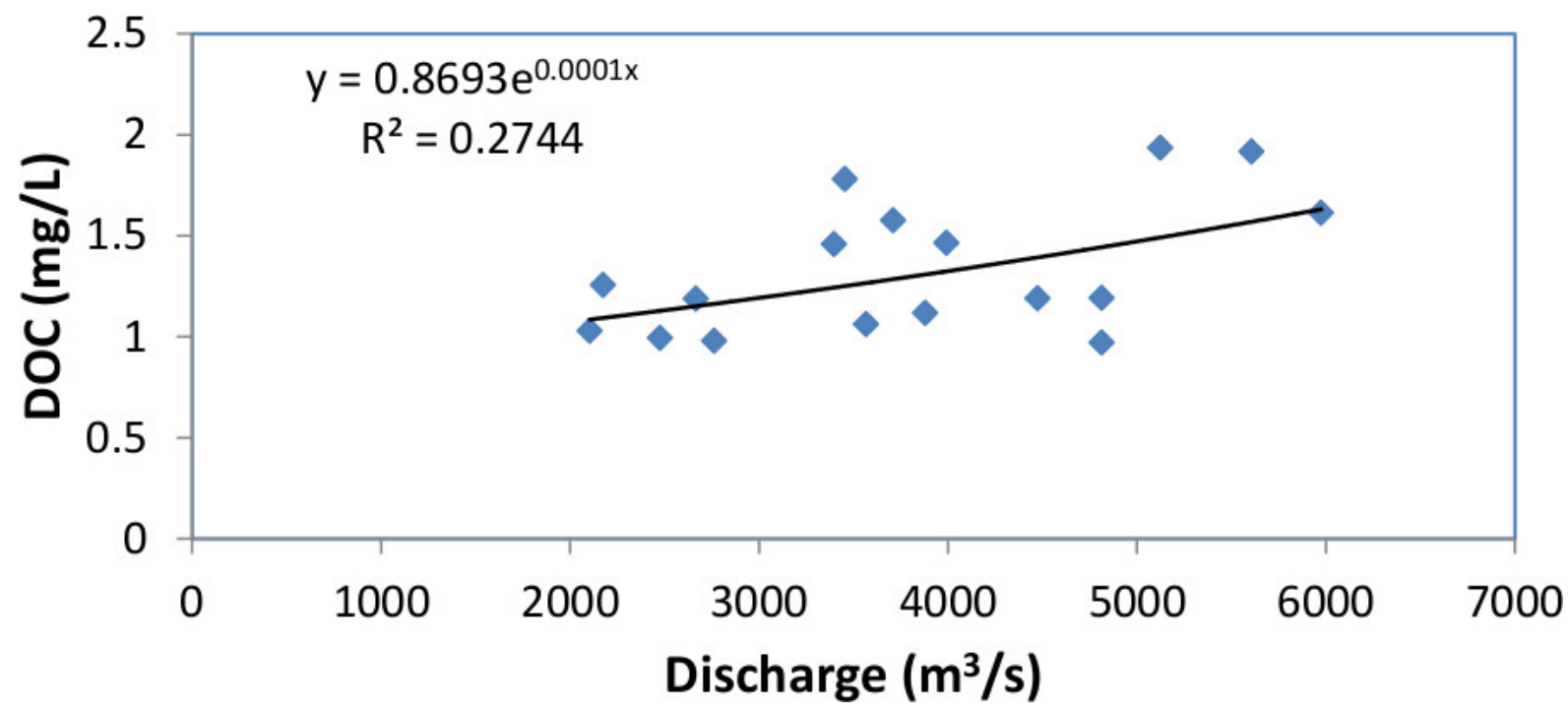

Figure S1. Relationship between observed DOC and stream flow discharge. 